\title{
Pseudomonas sp. MT14, a Soil Isolate which Contains Two Large Catabolic Plasmids, One a TOL Plasmid and One Coding for Phenylacetate Catabolism and Mercury Resistance
}

\author{
By ROGER W. PICK UP, ROBERT J. LEWIS AND PETER A. WILliams* \\ Department of Biochemistry \& Soil Science, University College of North Wales, Bangor, \\ Gwynedd LL57 2UW, U.K.
}

(Received 14 July 1982; revised 3 September 1982)

\begin{abstract}
Pseudomonas sp. MT14, isolated from soil as a result of its ability to utilise $m$-toluate as sole source of carbon, contains two large catabolic plasmids. One of these, pWW14, is a TOL plasmid of about $270 \mathrm{~kb}$ which determines the ability to grow on toluene, $m$-xylene and $p$-xylene as sole carbon sources. The other, $\mathrm{pWW} 17$, which is about $280 \mathrm{~kb}$, determines both the ability to grow on phenylacetate and resistance to mercury salts. Growth of MT14 on benzoate results in the segregation of derivatives in which either (i) one or both plasmids are completely lost, or (ii) one or both plasmids have undergone a large deletion which results in a change in the phenotype determined by that plasmid. Deletion of about $100 \mathrm{~kb}$ from pWW14 results in a regulatory mutation which allows its host to grow on $m$-xylene but not on its metabolite $m$-toluate (B3 mutants). Deletion of about $95 \mathrm{~kb}$ from pWW17 results in loss of the ability of its host to grow on phenylacetate but the mercury resistance is not lost.
\end{abstract}

\section{INTRODUCTION}

Pseudomonas sp. MT14 was one of 13 soil bacteria isolated by selective enrichment on $\mathrm{m}$ toluate as sole carbon source (Williams \& Worsey, 1976). After growth on benzoate/minimal medium for about 20 generations, all the isolates spontaneously segregated derivatives which utilized benzoate by the ortho pathway, distinguishing them from wild-type strains which used the meta pathway. This irreversible change, identical to that previously described in Pseudomonas putida mt-2, containing the TOL plasmid pWW0 (Williams \& Murray, 1974; Worsey \& Williams, 1975), was the chief reason for proposing that all the new isolates contained TOL plasmids isofunctional to $\mathrm{pWW} 0$. The mutant strains were routinely identified as a result of their loss of ability to grow on the TOL-specific substrates $m$-xylene and $m$-toluate $\left(\mathrm{Mxy}^{-} \mathrm{Mtol}^{-}\right)$.

Strain MT14 was one of a subgroup of three strains which segregated an additional class of mutants after growth on benzoate. These (called the B3 mutants) were able to grow on $m$-xylene by the plasmid-determined meta pathway, but could not grow on $m$-toluate, although it is a metabolite of $m$-xylene, and metabolized benzoate by the chromosomal ortho pathway (Williams \& Worsey, 1976). Genetic analysis of one member of this subgroup, $P$. putida MT20, indicated that the B3 phenotype resulted from a mutation, probably by deletion, of a regulatory gene $x y l S$, the gene product of which mediated induction by benzoate and $m$-toluate of the lower half of the catabolic pathway (Worsey \& Williams, 1977). Physical verification of the involvement of plasmids in this phenomenon has been hampered by the absence of a method which, in our hands, could isolate plasmid DNA reproducibly from these strains. The recent development of such a method (Wheatcroft \& Williams, 1981) has enabled us to show that $P$. putida MT20 contains a plasmid pWW20, of about $275 \mathrm{~kb}$, and that the B3 mutants result from a deletion in the plasmid which varies from 90 to $100 \mathrm{~kb}$ in independently isolated mutants (Pickup \& 
Williams, 1982). In this paper we report a similar investigation of the plasmid DNA in Pseudomonas strain MT14. This strain contains a plasmid pWW14 which, like pWW20, deletes a large region to form mutants with the B3 phenotype. MT14 also contains a second large plasmid, pWW17, determining catabolism of phenylacetic acid $\left(\mathrm{C}_{6} \mathrm{H}_{5} \cdot \mathrm{CH}_{2} . \mathrm{COOH}\right)$ and mercury resistance. Plasmid pWW17 also can undergo a large spontaneous deletion which results in loss of its catabolic phenotype.

\section{METHODS}

Bacterial strains and their maintenance. All the bacterial strains used in this work are listed in Table 1. They were maintained on nutrient agar slopes or on minimal agar stock plates containing single selective carbon sources at $5 \mathrm{~mm}$. Their ability to grow on $m$-xylene was tested by patching single colonies on to minimal agar plates, which were inverted and had small tubes containing liquid $m$-xylene placed in the lid.

Mercury resistance. Two methods were used routinely to test for resistance. For screening a large number of colonies, patches were made on minimal agar containing $10 \mathrm{~mm}$-succinate as carbon source and $10 \mu \mathrm{g} \mathrm{HgCl}_{2} \mathrm{ml}^{-1}$. For confirmation of the resistance of purified strains, a series of parallel streaks of the test strains were made on nutrient agar plates across which were laid strips of dry Whatman no. 1 filter paper $(2 \times 80 \mathrm{~mm})$ into which $20 \mu \mathrm{l}$ of $1 \mathrm{mg} \mathrm{HgCl} \mathrm{ml}^{-1}$ had previously been absorbed. Resistant strains grew to within 3 to $4 \mathrm{~mm}$ of the strip whereas sensitive strains were inhibited from growing to within about $20 \mathrm{~mm}$ of the strip.

Benzoate selection of derivative strains. A $5 \mathrm{ml}$ overnight nutrient broth-grown culture of MT14 was diluted by $10^{-5}$ in phosphate buffer, $\mathrm{pH}$. A sample $(0 \cdot 1 \mathrm{ml})$ of this dilution was inoculated into $5 \mathrm{ml}$ of $5 \mathrm{~mm}$ benzoate/minimal medium and incubated at $30^{\circ} \mathrm{C}$. When maximum turbidity was reached after about $2 \mathrm{~d}$, the culture was diluted and spread on nutrient agar plates. Single colonies were picked and tested for their ability to grow on $m$-xylene, $m$-toluate, phenylacetate and succinate/mercury agar plates.

Plasmid isolation and digestion. Plasmids were isolated by the method of Wheatcroft \& Williams (1981). Restriction endonuclease digestion, agarose gel electrophoresis, photography and analysis of the digest photographs were as previously described for large Pseudomonas plasmids (Wheatcroft \& Williams, 1981 ; Pickup \& Williams, 1982).

Conjugation experiments. (a) Plate matings. Equal volumes of overnight broth cultures of donor and recipient were mixed and $0.1 \mathrm{ml}$ portions of $10^{-1}$ and $10^{-2}$ dilutions were spread on selection plates. (b) Liquid matings. Equal volumes of unshaken overnight broth cultures of donor and recipient were mixed in a McCartney bottle and incubated at $30^{\circ} \mathrm{C}$ without shaking for 1 to $2 \mathrm{~h}$ prior to spreading on selection plates. (c) Filter matings. Mixed donor and recipient cultures were filtered through a $0.45 \mu \mathrm{m}$ Millipore filter, which was then laid on a nutrient agar plate and incubated at $30^{\circ} \mathrm{C}$ overnight. The filter was removed and the accumulated bacterial growth was resuspended in phosphate buffer, $\mathrm{pH} 7$, prior to spreading on selection plates.

\section{RESULTS}

\section{Benzoate selection}

To elucidate whether any of the plasmids which determined the TOL phenotype in our soil isolates also determined any other phenotypic characters, we compared the utilization of a range of potential growth substrates and the resistances to drugs and heavy metal salts of our wild-type strains and their cured derivatives. Strain MT14 was the only one to show any such differences, which were in its ability to grow on phenylacetate $\left(\mathrm{Paa}^{+}\right)$and its resistance to inorganic mercuric salts $\left(\mathrm{Hg}^{\mathrm{r}}\right)$. However, with the small number of mutants of MT14 originally available results were ambiguous and different derivative strains of MT14 appeared to have different phenotypes. We therefore screened a large number of individual colonies after growth of MT14 in benzoate/minimal medium: this is a very strong selection against wild-type since after about 20 generations virtually $100 \%$ of the colonies examined have lost the wild-type phenotype (Williams \& Worsey, 1976). From several experiments we isolated eight different derivatives, all distinguishable from wild-type MT14 (Table 1). In some (MT14-26, MT14-27) the TOL phenotype $\left(\mathrm{Mxy}^{+} \mathrm{Mtol}^{+}\right)$was retained, whereas some (MT14-103, MT14-104, MT14-105) were B3 mutants $\left(\mathrm{Mxy}^{+} \mathrm{Mtol}^{-}\right)$and others (MT14-100, MT14-101, MT14-102) had lost the TOL phenotype altogether $\left(\mathrm{Mxy}^{-} \mathrm{Mtol}^{-}\right)$. Apparently independently of the TOL phenotype, the ability to resist toxic concentrations of mercury and to grow on phenylacetate segregated independently of each other, except that we did not find any strains which were $\mathrm{Paa}^{+} \mathbf{H g}^{\mathrm{s}}$ : however the combinations $\mathrm{Paa}^{+} \mathrm{Hg}^{\mathrm{r}}, \mathrm{Paa}^{-} \mathrm{Hg}^{\mathrm{r}}$ and $\mathrm{Paa}^{-} \mathrm{Hg}^{\mathrm{s}}$ were all identified (Table 1). The 
(g)

(h)

(i)

(j)

(k)

(l)

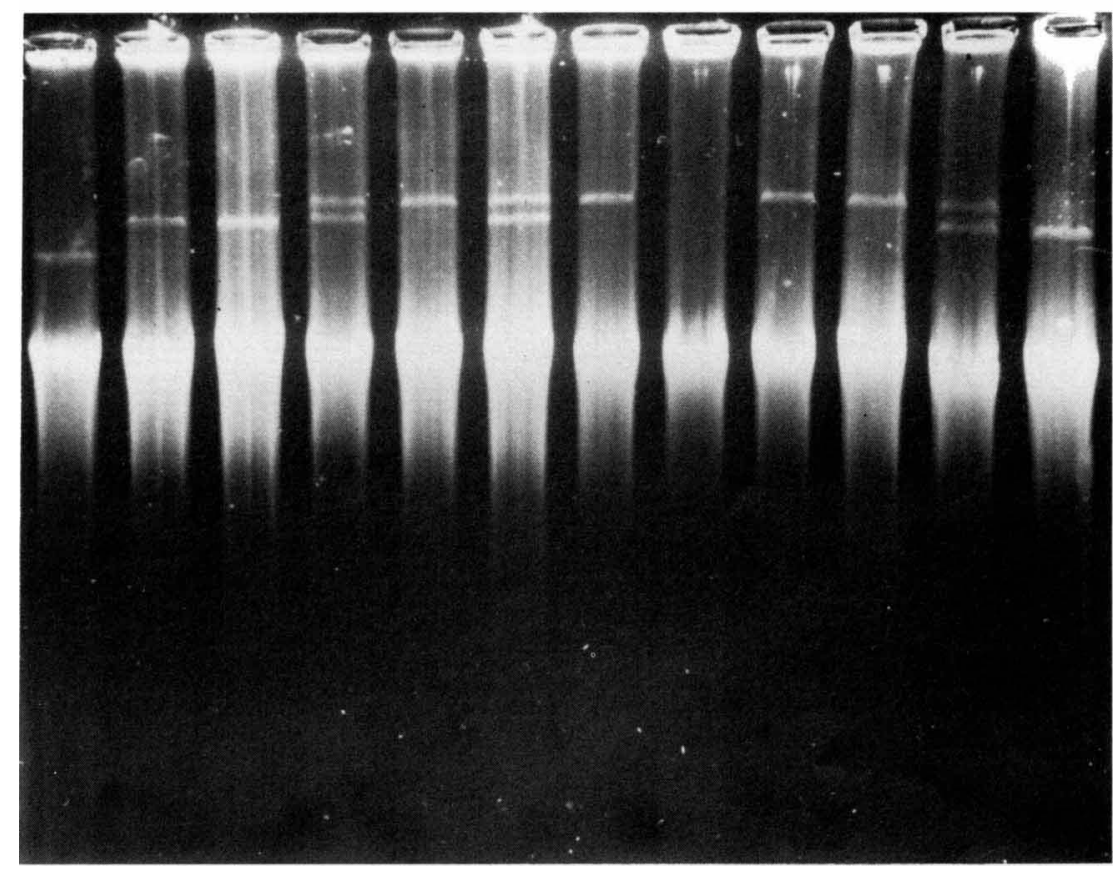

Fig. 1. Agarose gel electrophoresis of plasmid extracts of bacterial strains. (a) PaW1, (b) MT14-105, (c) MT14-104, (d) MT14-103, (e) MT14, ( $f)$ MT14-27, $(g)$ MT14-26, (h) MT14-102, $(i)$ MT14, $(j)$ MT14100, (k) MT14-27, (l) MT14-101.

Table 1. Bacterial strains

Strain

Pseudomonas sp. MT14 wild-type MT14-26

MT14-27

MT14-100

MT14-101

MT14-102

MT14-103

MT14-104

MT14-105

MT14-106

PaWl (P. putida $\mathrm{mt}-2$

wild-type)

PaW340
Relevant phenotype*

\begin{tabular}{|c|}
\hline $\mathrm{Mxy}^{+} \mathrm{Mtol}^{+} \mathrm{Paa}^{+} \mathrm{Hg}^{\mathrm{r}}$ \\
\hline 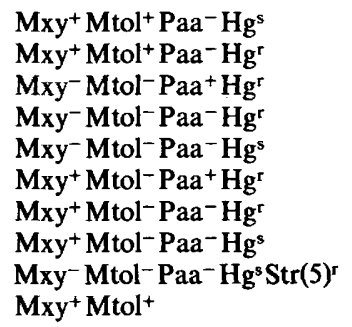 \\
\hline
\end{tabular}

Plasmid content pWW14, pWW17

pWW14

pWW14, pWW17-1

pWW17

pWW17-1

pWW14-1, pWW17

pWW14-1, pWW17-1

pWW14-1

pWW0
Reference or source

Williams \& Worsey (1977)

This paper

This paper

This paper

This paper

This paper

This paper

This paper

This paper

This paper

Williams \& Murray (1974)

C. J. Duggleby

* Phenotype designations: $\mathrm{Mxy}^{+}, \mathrm{Mtol}^{+}, \mathrm{Paa}^{+}$, abilities to grow on $m$-xylene, $m$-toluate and phenylacetate, respectively; $\mathrm{Hg}^{\mathrm{r}}$, resistance to mercuric salts; $\mathrm{Str}^{\mathrm{r}}$, resistance to streptomycin (concentration in $\mu \mathrm{g} \mathrm{ml}^{-1}$ ); $\mathrm{Trp}^{-}$, requirement for tryptophan.

frequency of occurrence of the various phenotypes fluctuated wildly in different experiments. One clone with each distinguishable phenotype was retained, and these all originated from three experiments.

\section{Plasmid analysis}

Agarose gel electrophoresis of cell lysates gave very confusing results (Fig. 1). Some strains (MT14, MT14-26, MT14-100) appeared to contain one large plasmid, others (MT14-101, MT14- 


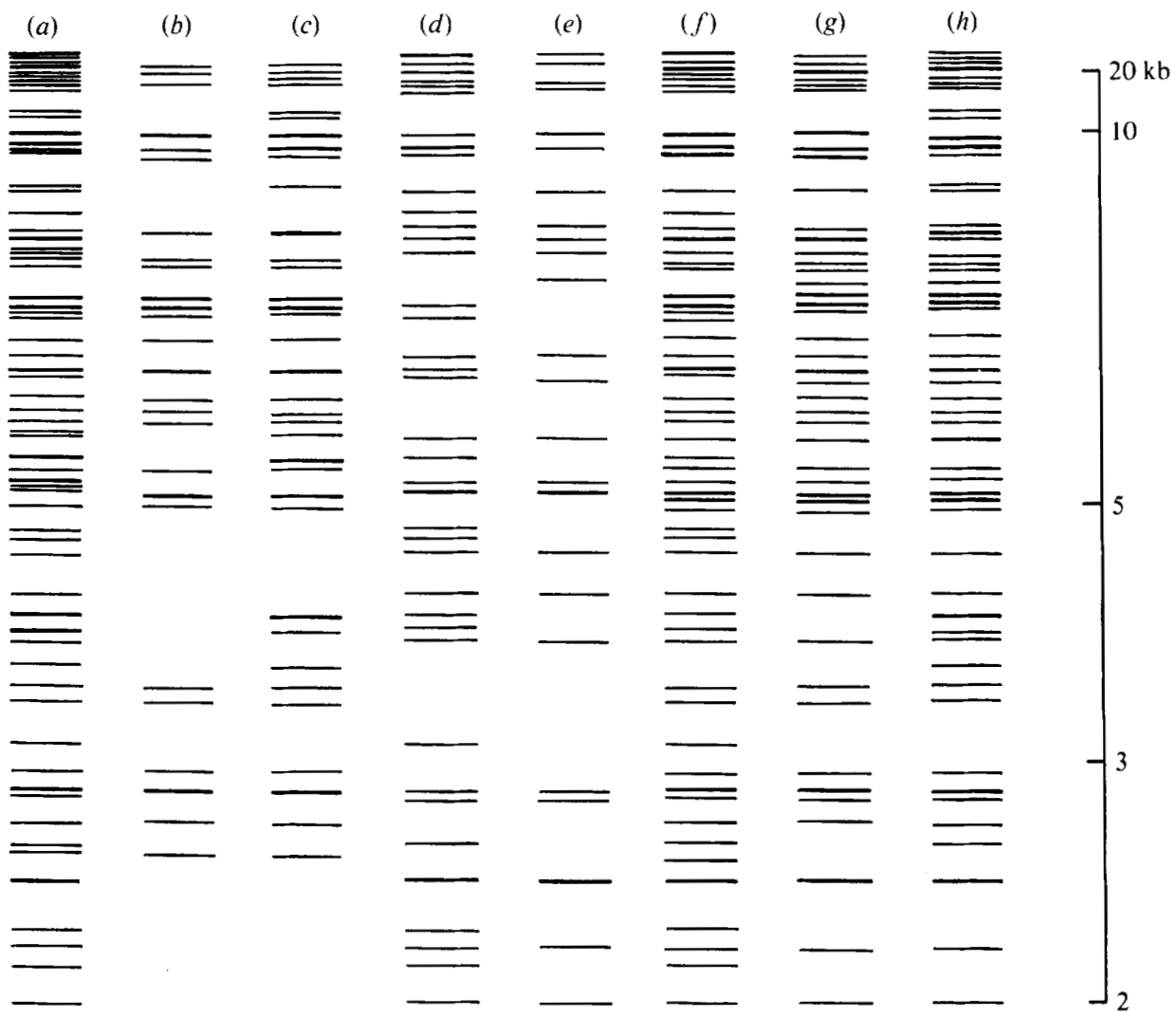

Fig. 2. Diagrammatic representation of gel electrophoresis of EcoRI digests of the plasmid DNA from bacterial strains: (a) MT14, (b) MT14-105, (c) MT14-26, (d) MT14-100, (e) MT14-101, ( $f$ ) MT14-103, (g) MT14-104, (h) MT14-27.

104, MT14-105) contained a single smaller plasmid larger than the $117 \mathrm{~kb}$ pWW0 control, and two (MT14-27, MT14-103) contained one plasmid of each size: MT14-102 contained no detectable plasmid DNA at all.

A possible explanation for this only became apparent when a detailed analysis of the plasmid DNA in P. putida MT20 showed that the plasmids in its B3 mutants had all undergone a deletion sufficiently large to make them distinguishable, on the basis of their electrophoretic mobility in agarose gels, from the parental pWW20 (Pickup \& Williams, 1982). Examination of Fig. 1 revealed that all the $\mathrm{Mxy}^{+} \mathrm{Mtol}^{+}$strains contain a large plasmid whereas all the $\mathrm{B} 3$ mutants contain a smaller plasmid. Similarly all the $\mathrm{Paa}^{+} \mathrm{Hg}^{\mathrm{r}}$ strains also contain a large plasmid whereas all the $\mathrm{Paa}^{-} \mathrm{Hg}^{\mathrm{r}}$ strains contain a plasmid of the smaller size. Figure 1 is explicable if MT14 contains two large plasmids, indistinguishable on agarose gel electrophoresis, both of which can undergo deletions of similar size, one to give the phenotype of the B3 mutants and one to give the $\mathrm{Paa}^{-} \mathrm{Hg}^{\mathrm{r}}$ phenotype. these plasmids could also be lost to give the $\mathrm{Mxy}^{-} \mathrm{Mtol}^{-}$and the $\mathrm{Paa}^{-} \mathrm{Hg}^{\mathrm{s}}$ phenotypes respectively: thus $\mathrm{MT14}-102\left(\mathrm{Mxy}^{-} \mathrm{Mtol}^{-} \mathrm{Paa}^{-} \mathrm{Hg}^{\mathrm{s}}\right)$ has no detectable plasmid DNA.

This hypothesis can be easily tested. Four of the strains should contain single plasmids. MT14-26 should contain only the wild-type TOL plasmid (which we have named pWW14) whereas MT14-105 should contain a deleted derivative of it (pWW14-1): restriction digests of the plasmid DNA in the two strains should be obviously related. Similarly MT14-100 should contain only the wild-type $\mathrm{Paa}^{+} \mathrm{Hg}^{\mathrm{I}}$ plasmid (pWW17) whereas MT14-101 should contain a 
deleted variant of it (pWW17-1). Comparison of restriction enzyme digests of each pair of strains should be very similar with all the fragments in the deleted plasmid being present in the parental plasmid except perhaps for one novel band formed from the fusion of the two fragments containing the deletion termini. Cross-comparison between the pairs should show little or no similarity. Furthermore, if the hypothesis is correct all the other strains, including MT14 but excluding MT14-102, should contain two plasmids each one of which should be identical (or at least very similar if the deletions in the various strains are not identical) to one of the plasmids in the single-plasmid strains. Thus, for example, MT14-104 should contain two plasmids similar or identical to pWW14-1 and pWW17-1, present singly in MT14-105 and MT14-101 respectively. Thus a restriction enzyme digest of the plasmid DNA extracted from MT14-104 should be virtually identical to a digest of a mixture of the plasmid DNA from MT14-105 and MT14-101.

We have tested and confirmed the hypothesis by comparing the restriction digests of the plasmid DNA from single strains and of mixtures of the DNA from pairs of strains.

The differences between MT14-26 and MT14-105 (Fig. 2) were as expected for a deletion in the latter's plasmid: estimation of the sizes of the plasmids by summing the fragment sizes indicated that pWW14 is about $270 \mathrm{~kb}$ and that $\mathrm{pWW} 14-1$ is about $170 \mathrm{~kb}$, showing that about $100 \mathrm{~kb}$ was deleted to form the B3 mutant. The digests from MT14-100 and MT14-101 were both very different to those from MT14-26 and MT14-104 but were similar to each other in the expected way. The estimates of their plasmid sizes were that pWW17 is about $280 \mathrm{~kb}$ and has undergone a deletion of about $95 \mathrm{~kb}$ when $\mathrm{pWW} 17-1$ was formed.

In all the following comparisons of the putative two-plasmid strains with mixed plasmid DNA from the single plasmid strains the two were indistinguishable (the mixtures are shown in parentheses): MT14-103 (MT14-105 + MT14-100); MT14-27 (MT14-26 + MT14-101); MT14104 (MT14-105 + MT14-101). Demonstration that MT14 plasmid DNA was identical to the combination of $\mathrm{pWW} 14$ and $\mathrm{pWW} 17$ (in MT14-26 and MT14-100) was the least satisfactory of the comparisons because resolution of the large number of bands was never good enough for an absolute verification of identity: however, given the poor resolution the two digests could not be distinguished.

\section{Plasmid transfer}

We have been unable to transfer by conjugation any of the plasmid-determined phenotypes from MT14 or any of its derivatives into either PaW340 (a plasmid-free $\operatorname{Str}^{r} \operatorname{Trp}^{-}$mutant of $P$. putida mt-2) or into MT14-106 (a Str ${ }^{\mathrm{r}}$ mutant of MT14-102). Both plasmids and their deleted variants therefore appear to be non-conjugative.

\section{DISCUSSION}

In this paper we have shown that Pseudomonas sp. MT14 contains two large plasmids. In addition to the TOL plasmid pWW14, it also contains a second catabolic plasmid pWW17 determining phenylacetate utilization, not previously reported in the literature as being plasmidencoded, as well as mercury resistance.

Growth of strains carrying TOL plasmids on benzoate selects for mutants which have lost the ability to grow on benzoate by the plasmid-determined meta pathway and which grow at a faster rate on benzoate by the chromosomal ortho pathway (Williams \& Murray, 1974; Worsey \& Williams, 1977). In the case of $P$. putida MT20 this selection can lead to deletion of a regulatory gene to give B3 mutants (Worsey \& Williams, 1977; Pickup \& Williams, 1982). Phenotypically and biochemically identical derivatives of strain MT14 also segregated during growth on benzoate: MT14-103, MT14-104 and MT14-105 are examples of such B3 mutants. Alternatively MT14-100, MT14-101 and MT14-102 have lost the entire TOL plasmid and with it their capacity to grow on any of the TOL-specific substrates. The similarity in behaviour between pWW 14 and pWW20 was reinforced by the close similarity in their restriction digest patterns (data not presented).

It is more difficult to explain why growth on benzoate selected for loss of the ability to grow on phenylacetate as found in MT14-27, MT14-101 and MT14-104 where pWW17 had undergone 
deletion of essential structural and/or regulatory gene(s) of the phenylacetate pathway, or as in MT14-26, MT14-102 and MT14-105 where the plasmid is lost altogether. The plasmid itself is not inherently unstable since the phenotypes of all the strains in Table 1 were maintained without detectable loss $(<1 \%)$ through about 100 generations in nutrient broth. A similar argument to that used to explain the benzoate-selected loss of the TOL phenotype would require that benzoate is a metabolite of phenylacetate but that it supports slower growth by that pathway than by the ortho pathway. We have not been able to demonstrate the biochemical route by which phenylacetate is metabolized in MT14, but we are not alone in that respect since other laboratories have suffered the same difficulties with some phenylacetate-utilizing isolates (S. Dagley, personal communication). In the few examples where pathways have been worked out, either homogentisate (Dagley et al., 1953) or homoprotocatechuate (Kunita, 1955) have been shown to be metabolites, but not benzoate. It is possible that elucidation of the pathway in MT14 would provide a biochemical explanation for the selection of $\mathrm{Paa}^{-}$mutants. However, we have found that growing MT14-100 through five successive cycles of benzoate medium results in no $\mathrm{Paa}^{-}$strains.

One possible implication of these results is that pWW17 at some stage in its past history has acquired a region of DNA encoding phenylacetate catabolism, possibly a transposon or similar element, originally associated with another replicon: its deletion could be a reflection of its modular construction. An investigation of the termini of the deletion would be one way of throwing light on this possibility, but the large size of the plasmid makes conventional structural studies impossible at present.

These results are a further demonstration that the association of catabolic genes with plasmids can lead to spontaneous instability of the catabolic phenotypes when the host strains are subject to nutritional selection. This may be a major factor accounting both for the inherent instability of many soil saprophytic bacteria when cultured under laboratory conditions and also for the evolution and spread of catabolism in natural populations.

\section{REFERENCES}

Dagley, S., Fewster, M. E. \& HAPPOld, F. C. (1953). The bacterial oxidation of aromatic compounds. Journal of General Microbiology 8, 1-7.

KUNITA, N. (1955). Bacterial oxidation of phenylacetic acid. I. The pathway through homoprotocatechuic acid. Medical Journal of Osaka University 6, 697-702.

PickuP, R. W. \& Williams, P. A. (1982). Spontaneous deletions in the TOL plasmid pWW20 which give rise to the B3 regulatory mutants of $P_{\text {seudomonas }}$ putida MT20. Journal of General Microbiology 128, 1385-1390.

Wheatcroft, R. \& Williams, P. A. (1981). Rapid methods for the study of both stable and unstable plasmids in Pseudomonas. Journal of General Microbiology 124, 433-437.

Williams, P. A. \& Murray, K. (1974). Metabolism of benzoate and the methylbenzoates by Pseudomonas putida (arvilla) mt-2: evidence for the existence of a TOL plasmid. Journal of Bacteriology 120, 416-423.

Williams, P. A. \& WORSEY, M. J. (1976). Ubiquity of plasmids in coding for toluene and xylene metabolism in soil bacteria: evidence for the existence of new TOL plasmids. Journal of Bacteriology 125, 818828.

Worsey, M. J. \& Williams, P. A. (1975). Metabolism of toluene and xylenes by Pseudomonas putida (arvilla) mt-2: evidence for a new function of the TOL plasmid. Journal of Bacteriology 124, 7-13.

Worsey, M. J. \& Williams, P. A. (1977). Characterisation of a spontaneously occurring mutant of the TOL20 plasmid in Pseudomonas putida MT20: possible regulatory implications. Journal of Bacteriology 130, 1149-1158. 